\title{
A comparison of fluctuations of Campylobacter and Escherichia coli concentrations on broiler chicken carcasses during processing in two slaughterhouses
}

\author{
Ewa Pacholewicz ${ }^{\text {a,b,* },}$, Arno Swart ${ }^{c}$, Maarten Schipper ${ }^{c}$, Betty G.M. Gortemaker ${ }^{\text {a }}$, Jaap A. Wagenaar ${ }^{\text {d,e,f }}$, \\ Arie H. Havelaar ${ }^{\text {g,a,c, }}$, Len J.A. Lipman ${ }^{\text {a }}$ \\ a Division Veterinary Public Health, Institute for Risk Assessment Sciences, Utrecht University, Utrecht 3508 TD, The Netherlands \\ b MEYN Food Processing Technology B.V., Oostzaan, 1511 MA, The Netherlands \\ c Centre for Infectious Disease Control, National Institute for Public Health and the Environment, Bilthoven, 3720 BA, The Netherlands \\ d Department of Infectious Diseases and Immunology, Faculty of Veterinary Medicine, Utrecht University, Utrecht 3508 TD, The Netherlands \\ e Central Veterinary Institute of Wageningen UR, Lelystad, The Netherlands \\ ${ }^{\mathrm{f}}$ WHO-Collaborating Center for Campylobacter/OIE Reference Laboratory for Campylobacteriosis, Utrecht/Lelystad, The Netherlands \\ ${ }^{g}$ Emerging Pathogens Institute, University of Florida, Gainesville, FL, USA \\ h Department of Animal Sciences, University of Florida, Gainesville, FL, USA
}

\section{A R T I C L E I N F O}

\section{Article history:}

Received 24 July 2014

Received in revised form 27 March 2015

Accepted 3 April 2015

Available online 10 April 2015

\section{Keywords:}

Poultry

Slaughter hygiene

Process Hygiene Criteria

\begin{abstract}
A B S T R A C T
The causes of differences in Campylobacter and Escherichia coli concentrations on broiler chicken carcasses after chilling between slaughterhouses are not fully identified. Therefore, it is a challenge for slaughterhouses to comply with Process Hygiene Criteria for broiler meat.

The aim of the study was to identify which processing steps contribute to increases or decreases in Campylobacter and $E$. coli concentrations within and between two slaughterhouses. Identifying the processing steps with variable performance could explain the differences in bacterial concentrations after chilling between slaughterhouses. Thermotolerant Campylobacter and E. coli concentrations on carcasses during broiler processing were measured during the summer period in 21 trials after bleeding, scalding, defeathering, evisceration and chilling. In two slaughterhouses with comparable Campylobacter and E. coli concentrations in the incoming batches (after bleeding), the mean $\log _{10}$ concentrations are found to be significantly different after chilling. Campylobacter concentrations decreased by $1.40 \log _{10}$ in Slaughterhouse 1 and by $1.86 \log _{10}$ in Slaughterhouse 2, whereas E. coli decreased by $2.19 \log _{10}$ in Slaughterhouse 1 and by $2.84 \log _{10}$ in Slaughterhouse 2. Higher concentrations of Campylobacter and E. coli on carcasses after chilling were observed in Slaughterhouse 1 in which an increase in concentrations was observed after evisceration. The effect of processing on Campylobacter and E. coli concentrations in Slaughterhouse 1 did not differ between batches. In Slaughterhouse 2, the effect of processing on the concentrations of both bacteria varied over batches. Changes in E. coli concentration levels during processing were similar to Campylobacter except for defeathering. E. coli concentration significantly decreased after defeathering in both slaughterhouses, whereas Campylobacter increased in Slaughterhouse 2 and in Slaughterhouse 1 no significant changes were observed. The patterns of increases and decreases in bacterial concentrations during processing are specific for each slaughterhouse. Inhomogeneous patterns potentially explain the differences in concentrations after chilling between slaughterhouses. Critical processing steps should be validated in each slaughterhouse by longitudinal studies and potentially based on E. coli. E. coli has a potential to be used as an indicator of processing hygiene, because the impact of most of the studied processing steps was similar as for Campylobacter.
\end{abstract}

(c) 2015 Elsevier B.V. All rights reserved.

\section{Introduction}

Campylobacter has remained the major gastrointestinal bacterial pathogen in humans in the European Union (EU) since 2005 (European

* Corresponding author at: Yalelaan 2, PO Box 80175, 3508 TD Utrecht, The Netherlands. Tel: + 3130253 2347; fax: + 31302532365

E-mail address: e.pacholewicz@uu.nl (E. Pacholewicz).
Food Safety Authority, 2014). The annual number of campylobacteriosis cases was estimated at 9 million in the European Union (Havelaar et al., 2009). Broiler meat is recognised as a major source of human infections. An estimated $20-30 \%$ of cases of campylobacteriosis in EU may be attributed to the handling, preparation and consumption of broiler meat (European Food Safety Authority, 2010a). According to risk assessment studies, the most effective reduction of human infections in the short term could be achieved by reducing Campylobacter numbers in 
contaminated slaughtered batches (Nauta et al., 2009). Compliance of batches sold as fresh meat with a threshold value of 1000 or $500 \mathrm{CFU} / \mathrm{g}$ of neck and breast skin would reduce the health risk by more than $50 \%$ or even 90\% (European Food Safety Authority, 2011). These risk assessment results drive the initiative to establish Process Hygiene Criteria (PHC) for broiler meat to stimulate further control measures aiming at reducing carcass contamination (European Food Safety Authority, 2012a). Moreover, the PHC could be used as a tool to classify slaughterhouses according to their capability to prevent or reduce hazards and as a tool to monitor risk and verify hygiene management in slaughterhouses (European Food Safety Authority, 2012a). Compliance to the PHC is, however, a challenge for the industry. In $20 \%$ of the tested batches in the European Union, the Campylobacter concentrations in neck and breast skin after chilling exceeded 1000 CFU/g (European Food Safety Authority, 2010b). In The Netherlands, $30 \%$ of all produced batches would not meet the threshold of none of 5 samples per batch exceeding 1000 Campylobacter CFU/g of breast skin after chilling (Anonymous, 2011; Swart et al., 2013). Differences in Campylobacter concentrations after chilling between slaughterhouses were identified in the baseline surveys (Anonymous, 2011; European Food Safety Authority, 2010b). However, the causes of the differences were not fully identified. Campylobacter concentrations change along the processing line with typically a decrease after scalding and chilling, an increase after defeathering and an increase or no change after evisceration (Berrang and Dickens, 2000; Izat et al., 1988; Klein et al., 2007; Oosterom et al., 1983; Rosenquist et al., 2006; Seliwiorstow et al., 2012; Tchórzewska et al., 2013). It has not been investigated whether these changes in concentrations are maintained at similar levels between batches and between slaughterhouses. Identifying the processing steps with variable performance within and between slaughterhouses could explain the differences in Campylobacter concentrations after chilling and thus improve the ability of the slaughterhouses to comply with potential Process Hygiene Criteria.

Setting a PHC based on Escherichia coli instead of on pathogenic bacteria has been proposed (European Food Safety Authority, 2012a; European Food Safety Authority, 2012b), because indicator microorganisms are recognised to reflect better the process hygiene than pathogenic microorganisms. The advantage of using $E$. coli to monitor processing performance is also related to easier, lowercost, omnipresent enumeration techniques and frequent occurrence of $E$. coli on the carcasses that is not impacted by seasonality as in the case of Campylobacter (European Food Safety Authority, 2012a; Habib et al., 2012). Furthermore, targets based on E. coli concentration levels on carcasses after chilling proved to be a useful tool to reduce Campylobacter levels on postchill carcasses (Habib et al., 2012).

The aim of the study was to identify which processing steps contribute to increases or decreases in Campylobacter and E. coli concentrations in two slaughterhouses. Moreover the purpose was to identify whether the impact of the processing steps on bacterial contamination levels varied within and between slaughterhouses and whether the impact was similar for both Campylobacter and E. coli.

\section{Materials and methods}

\subsection{Slaughterhouses}

The samples were taken in two commercial broiler chicken slaughterhouses. Slaughterhouse 1 is located in Germany and daily processes 130000 broilers, whereas Slaughterhouse 2 is situated in The Netherlands and daily processes 240000 broilers. The slaughterhouses were selected because of similarities in the processing equipment applied. During the study, the stunning, scalding and defeathering equipment was modernised in Slaughterhouse 1 prior to trials in 2013. The processing parameters remained the same.

\subsection{Collection and preparation of samples}

Thermotolerant Campylobacter and E. coli concentrations during broiler processing were measured in 21 trials. Eleven trials were performed in Slaughterhouse 1 (trials' ID: A, B, C, I, K, L, N, O, Q R, U). Ten trials were performed in Slaughterhouse 2 (trials' ID: D, E, F, G, H, J, M, P, S, $\mathrm{T}$ ). The trials were performed between June-October 2012 (trials A-M) and June-October 2013 (trials $\mathrm{N}-\mathrm{U}$ ). This sampling period was chosen in order to increase the probability of Campylobacter positive flocks (European Food Safety Authority, 2010c). Each trial was performed on a different day and included one batch, defined as a group of chickens raised together in one shed (European Food Safety Authority, 2011).

The Campylobacter status of the batch was ascertained by the slaughterhouses. In Slaughterhouse 1, bootswabs (in 2012 and 2013) and cloacal swabs (in 2012) at farms were taken 2-3 days prior to sampling in the slaughterhouse. The bootswabs were enriched in Campy Food broth (bioMérieux SA, Marcy l'Etoile, France), the cloacal swabs in Preston broth (prepared according to manufacturer guidelines - Oxoid). From the enrichment broth $1 \mathrm{ml}$ was taken for further analysis and the positivity was checked by PCR with a detection limit of 100 CFU/ml. In Slaughterhouse 2, faecal droppings were collected at farms one week prior to sampling in the slaughterhouse. The faecal droppings were streaked on mCCDA, incubated and confirmed according to a Dutch national method (Anonymous, 2010). The limit of detection was $100 \mathrm{CFU} / \mathrm{g}$.

During the trials, the first samples were collected after at least 1000 carcasses of the investigated batch had passed through the line, in order to avoid potential cross-contamination from the previously slaughtered batch. Samples were collected after the following processing steps: 1) just after bleeding, 2) just after scalding, 3) just after defeathering, 4) after evisceration and evisceration spraying cabinet but before inside and outside washing and 5) just after chilling. These steps were chosen, because the most dynamic changes in bacterial contamination levels were reported after these steps (Rosenquist et al., 2006).

The sampling plan to collect quantitative data is presented in Table 1. Whole carcass rinse was performed as described previously (Pacholewicz et al., 2013). The carcasses were removed from the line after selected processing steps. The cloacae of the non-eviscerated carcasses were plugged with a fibre tampon to prevent faecal and intestinal leakage while rinsing. Prevention of leakage of faecal material as a result of plugging was compared to results from rinsing the carcasses that were plugged and sealed (results not shown). Plugging and sealing of the vent were previously reported to prevent the faecal leakage (Berrang et al., 2001). After placing the carcasses into sterile plastic bags (Hevel, Zaandam, The Netherlands), $500 \mathrm{ml}$ of peptone saline was added and the carcasses were shaken by hands for 60 s (Anonymous, 2000; Nauta et al., 2007; Reich et al., 2008). The same volume of the rinse was used for carcasses with feathers, defeathered or eviscerated carcasses to overcome differences in bacterial recovery, because removal rate was reported to differ with different volumes of rinse fluid (Williams et al., 2010).

In addition positivity of caeca from carcasses sampled after evisceration was checked in trials J-U. Caecal material was plated on Campy Food Agar and in case of no growth, enrichment was done according to the Dutch national method (Anonymous, 2010).

Breast skin samples after chilling were additionally collected during trials in 2013. The purpose of collecting the breast skin samples was to compare results from rinse and breast skin. The skin samples were collected as previously described (Anonymous, 2011). In short: $25 \mathrm{~g}$ $(+/-5 \mathrm{~g})$ of skin from breast corpus was cut and placed in a stomacher bag.

Samples collected after different processing steps do not correspond to the same carcass, except for the caecal samples. These samples were collected from the same eviscerated carcasses that were sampled by the whole carcass rinse method.

The number of samples collected per trial for each sampling location was different (Table 1 ). In trials A-D - 3 samples were collected, in trials $\mathrm{E}-\mathrm{G}-4$ and in trials $\mathrm{H}-\mathrm{U}-8$. The difference in the number of 
Table 1

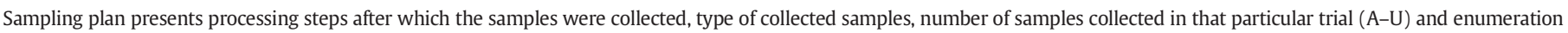
threshold.

\begin{tabular}{|c|c|c|c|c|c|c|c|c|c|c|c|c|c|c|c|c|c|c|c|c|c|c|c|c|c|}
\hline \multirow[t]{4}{*}{ Processing step } & \multirow[t]{4}{*}{ Sample type } & \multirow[t]{4}{*}{ Unit } & \multirow{4}{*}{$\begin{array}{l}\text { Enumeration threshold } \\
\text { CFU/ml or CFU/g } \\
\text { Campylobacter/E. coli }\end{array}$} & \multicolumn{13}{|c|}{ Trials 2012} & \multicolumn{8}{|c|}{ Trials 2013} & \multirow[t]{4}{*}{ Sum } \\
\hline & & & & $\mathrm{A}$ & B & C & $\mathrm{D}$ & $\mathrm{E}$ & $\mathrm{F}$ & G & $\mathrm{H}$ & I & $\mathrm{J}$ & $\mathrm{K}$ & $\mathrm{L}$ & $\bar{M}$ & $\mathrm{~N}$ & 0 & $\mathrm{P}$ & $\mathrm{Q}$ & $\mathrm{R}$ & $\mathrm{S}$ & $\mathrm{T}$ & $\bar{U}$ & \\
\hline & & & & \multicolumn{21}{|c|}{ Slaughterhouse 1 or Slaughterhouse 2} & \\
\hline & & & & $\overline{1}$ & 1 & 1 & 2 & 2 & 2 & 2 & 2 & 1 & 2 & 1 & 1 & 2 & 1 & 1 & 2 & 1 & 1 & 2 & 2 & 1 & \\
\hline After bleeding & $\begin{array}{l}\text { Whole carcass } \\
\text { rinse }\end{array}$ & $\mathrm{CFU} / \mathrm{ml}$ & $10 / 10$ & 3 & 3 & 3 & 0 & 4 & 4 & 4 & 8 & 8 & 8 & 8 & 8 & 8 & 8 & 8 & 8 & 8 & 8 & 8 & 8 & 8 & 133 \\
\hline After scalding & $\begin{array}{l}\text { Whole carcass } \\
\text { rinse }\end{array}$ & $\mathrm{CFU} / \mathrm{ml}$ & $1 / 10$ & 3 & 3 & 3 & 3 & 4 & 4 & 4 & 8 & 8 & 8 & 8 & 8 & 8 & 8 & 8 & 8 & 8 & 8 & 8 & 8 & 8 & 136 \\
\hline $\begin{array}{l}\text { After } \\
\quad \text { defeathering }\end{array}$ & $\begin{array}{l}\text { Whole carcass } \\
\text { rinse }\end{array}$ & $\mathrm{CFU} / \mathrm{ml}$ & $1 / 10$ & 3 & 3 & 3 & 3 & 4 & 4 & 4 & 8 & 8 & 8 & 8 & 8 & 8 & 8 & 8 & 8 & 8 & 8 & 8 & 8 & 8 & 136 \\
\hline After evisceration & $\begin{array}{l}\text { Whole carcass } \\
\text { rinse }\end{array}$ & $\mathrm{CFU} / \mathrm{ml}$ & $1 / 10$ & 3 & 3 & 3 & 3 & 4 & 4 & 4 & 8 & 8 & 8 & 8 & 8 & 8 & 8 & 8 & 8 & 8 & 8 & 8 & 8 & 8 & 136 \\
\hline \multirow[t]{2}{*}{ After chilling } & $\begin{array}{l}\text { Whole carcass } \\
\text { rinse }\end{array}$ & $\mathrm{CFU} / \mathrm{ml}$ & $1 / 1$ & 3 & 3 & 3 & 3 & 4 & 4 & 4 & 8 & 8 & 8 & 8 & 8 & 8 & 8 & 8 & 8 & 8 & 8 & 8 & 8 & 8 & 136 \\
\hline & Breast skin sample & $\mathrm{CFU} / \mathrm{g}$ & $10 / 10$ & 0 & 0 & 0 & 0 & 0 & 0 & 0 & 0 & 0 & 0 & 0 & 0 & 0 & 8 & 8 & 8 & 8 & 8 & 8 & 8 & 8 & 64 \\
\hline \multicolumn{4}{|c|}{ Total analysed samples } & 15 & 15 & 15 & 12 & 20 & 20 & 20 & 40 & 40 & 40 & 40 & 40 & 40 & 48 & 48 & 48 & 48 & 48 & 48 & 48 & 48 & 741 \\
\hline \multirow{2}{*}{\multicolumn{4}{|c|}{$\begin{array}{l}\text { Number of samples below Campylobacter enumeration threshold } \\
\text { Number of samples below } E \text {. coli enumeration threshold }\end{array}$}} & 8 & 0 & 0 & 0 & 0 & 0 & 1 & 1 & 19 & 0 & 1 & 0 & 0 & 0 & 7 & 0 & 1 & 0 & 7 & 1 & 0 & \\
\hline & & & & 0 & 0 & 0 & 0 & 0 & 0 & 0 & 0 & 0 & 0 & 0 & 0 & 1 & 0 & 0 & 0 & 0 & 0 & 2 & 0 & 0 & \\
\hline
\end{tabular}

samples between the trials was related to the fact that samples collected during trials A-G were not only analysed by the culture method but also by the PMA-qPCR method (Pacholewicz et al., 2013). The purpose was to validate the PMA-qPCR method for quantifying viable Campylobacter cells, as an alternative for the culture method. It was not feasible to analyse more samples per location with both methods. As the PMA-qPCR method was not validated, the culture method only was used in trials $\mathrm{H}-\mathrm{U}$ and more samples could be accommodated.

All collected samples were stored at $3{ }^{\circ} \mathrm{C}\left(+/-2{ }^{\circ} \mathrm{C}\right)$, as specified in ISO 10272-2 (Anonymous, 2006), until laboratory analysis. In the case of 15 trials (A, B, D-G, I, J, L, N, O, Q R, T, U) the samples were stored overnight. Due to the slaughter time of the batches and travelling time from the slaughterhouses to the laboratory, it was not feasible to perform the analytical work on the same day. Overnight storage of the rinse samples did not affect the number of recovered Campylobacter (results not shown). In the case of the remaining 6 trials $(\mathrm{C}, \mathrm{H}, \mathrm{K}, \mathrm{M}, \mathrm{P}, \mathrm{S})$ the analytical work was done on the day on which the samples were collected.

\subsection{Analytical methods}

The serial dilutions of whole carcass rinse samples were done in Butterfield's Buffer (3M The Netherlands, Zoeterwoude, product number BPPFV9BF) or peptone saline. No differences in counts were observed while using both media (results not shown). The breast skin samples were homogenised with 9 volumes of peptone saline. Serial dilutions of the homogenate were done in Butterfield's Buffer. Campylobacter enumeration was done on Campy Food Agar (bioMérieux SA, Marcy l'Etoile, France, product number 43471), according to ISO 10272-2 (Anonymous, 2006). Five Campylobacter presumptive colonies per sample were confirmed by microscopic observation after Gram staining. The Campylobacter isolates were not identified at species level. The enumeration threshold for the rinse samples was $10 \mathrm{CFU} / \mathrm{ml}$ for samples after bleeding, because higher concentrations were expected in the samples after bleeding than after the following steps or $1 \mathrm{CFU} / \mathrm{ml}$ for samples after scalding, defeathering, evisceration and chilling. The enumeration threshold for breast skin samples was $10 \mathrm{CFU} / \mathrm{g}$.

E. coli enumeration was done on Petri films ( $3 \mathrm{M}^{\mathrm{TM}}$ Petrifilm ${ }^{\mathrm{TM}}$ from $3 \mathrm{M}$, The Netherlands, Zoeterwoude, products numbers for $E$. coli $64140)$. Blue colonies with associated gas bubbles were counted with the $3 \mathrm{M}^{\mathrm{TM}}$ Petrifilm ${ }^{\mathrm{TM}}$ Plate Reader (Model 6499, 3M, Germany) after 24 hour incubation at $37^{\circ} \mathrm{C}$. The $E$. coli enumeration threshold for the rinse samples was $10 \mathrm{CFU} / \mathrm{ml}$ (samples after bleeding, scalding, defeathering, evisceration) and $1 \mathrm{CFU} / \mathrm{ml}$ (samples after chilling). The enumeration threshold for breast skin samples was $10 \mathrm{CFU} / \mathrm{g}$.

\subsection{Statistical analysis}

Several analyses were performed in order to identify, on a per slaughterhouse basis (1), whether trends (i.e. the whole pattern of increases and decreases over the processing steps) were different between the trials, and (2) which processing steps significantly increased or decreased the mean numbers of organisms on the carcasses. Furthermore, for each of these questions, it was analysed (3) whether the effect differed between the slaughterhouses. The analysis was performed separately for Campylobacter and E. coli.

The Campylobacter and E. coli concentrations (per $\mathrm{ml}$ of rinse sample and per $g$ of breast skin sample) were transformed to the $\log _{10}$ scale. The normality and homoscedasticity of the residuals were checked by diagnostic plots. Counts below the enumeration threshold were replaced by half the threshold according to Rosenquist et al., 2006. Sensitivity analysis was carried out to investigate the different replacements of the enumeration threshold. There was no effect of various replacements of the enumeration threshold on the results. Trials with many samples below enumeration threshold (around 50\%) or negative results from caeca were not included in the analysis. For statistical analysis we used trials that had consistent types of samples collected.

The models used to analyse the data did not accommodate zeros; therefore, $100 \%$ of prevalence in a positive batch was assumed. Data analysis was performed in R software, package lme4 (3.0.3, 2014, $\mathrm{R}$ development Core Team).

\subsubsection{Models developed for the identification of critical processing steps in a slaughterhouse}

Two linear mixed effect models were prepared to identify whether the impact of the processing steps varied between trials (Fig. 1). The first model had processing step as an explanatory factor and trial as a random effect (model 1$)$. In model 1 , the intercept $\left(\beta_{0}=\right.$ mean concentration level after bleeding) varied over trials $\left(b_{0}=\right.$ random effect over trials with mean 0 ) and the effect of the processing step (slope) was the same for each trial ( $\beta$ indicates a fixed effect), the residual error $(\varepsilon)$ varied over carcasses. The "Concentration" is the mean concentration $\left(\log _{10} \mathrm{CFU} / \mathrm{ml}\right)$ in samples collected after a particular step ("Scalding", 
Models to identify critical processing steps

IN a slaughterhouse

Model 1

intercept varied over trials, the effect of the processing step the same for each trial
Model 2

intercept and the effect of the processing step varied over trials

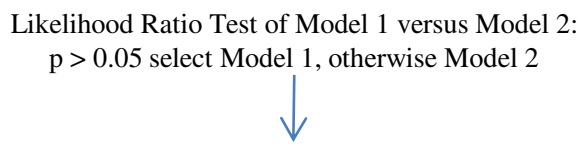

Compute increase or decrease in bacterial concentrations after particular processing step based on selected model

Fig. 1. Overview of selection of a model to identify the critical processing steps in a slaughterhouse.

Models to identify critical processing steps BETWEEN slaughterhouses

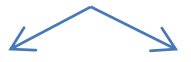

Model 1

intercept varied over trials, the effect of the processing step the same for each trial
Model 3

intercept varied over trials, the effect of the processing step the same for each trial.

Interaction between slaughterhouse and processing step

Likelihood Ratio Test of Model 1 versus Model 3: p $>0.05$ select Model 1, otherwise Model 3<smiles>C1=CC2C=CC(=C1)C2</smiles>

Compute differences between slaughterhouses in

increase or decrease in bacterial concentrations after particular processing step based on selected model

Fig. 2. Overview of selection of a model to identify the critical processing steps between the slaughterhouses.
“Defeathering”, “Evisceration”, “Chilling”, dummy variables with 1 for the respective process step and 0 otherwise).

Concentration $=b_{0}+\beta_{0}+\beta_{1}$ Scalding $+\beta_{2}$ Defeathering

$$
+\beta_{3} \text { Evisceration }+\beta_{4} \text { Chilling }+\varepsilon
$$

In the second model, not only the intercept (initial concentration level after bleeding) varied over trials, but also the impact of the processing step (slope). The random effects $b_{i}$ were added to each processing step.

Concentration $=b_{0}+\beta_{0}+\left(b_{1}+\beta_{1}\right)$ Scalding $+\left(b_{2}+\beta_{2}\right)$ Defeathering

$$
+\left(b_{3}+\beta_{3}\right) \text { Evisceration }+\left(b_{4}+\beta_{4}\right) \text { Chilling }+\varepsilon
$$

Since model 1 and model 2 are nested models, the comparison was done using a likelihood ratio test. Based on the selected model (model 1 or model 2), an increase or decrease in bacterial concentration after particular processing steps (effect of a processing step) was computed at each slaughterhouse. The effects of the processing steps were calculated as e.g. the predicted concentration after defeathering minus the predicted concentration after scalding.
2.4.2. Models developed for the identification of critical processing steps between slaughterhouses

In the following analyses it was computed whether, and if so, how the impact of processing steps differed between slaughterhouses (Fig. 2). Model 1 was run fitting the data from both slaughterhouses together. It was analysed whether the impact of the processing steps was the same at both slaughterhouses.

Another model was prepared (model 3 ) to address the question whether the patterns of the impact of the subsequent processing steps differ between the slaughterhouses. An interaction formula between slaughterhouses and processing step was added to the model 3.

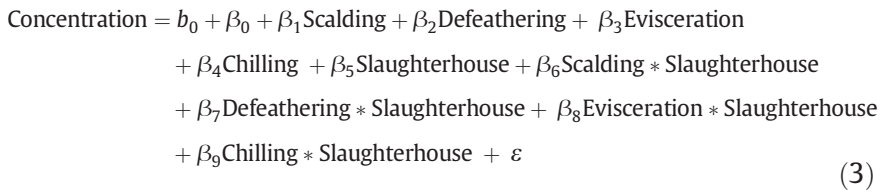

Models 1 and 3 were nested and, thus, compared by the likelihood ratio test. The significance of any coefficients $\beta_{6}$ to $\beta_{9}$ indicated a difference between the slaughterhouses for the respective processing step. The differences in the effect at processing step were calculated with Slaughterhouse 1 as the reference, as e.g. predicted concentration after defeathering minus the predicted concentration after scalding in Slaughterhouse 2 subtracted from the predicted concentration after 
Table 2

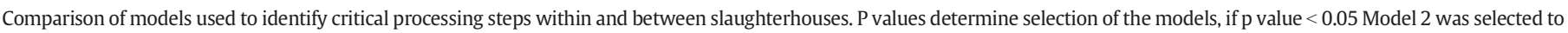
identify critical processing steps within a slaughterhouse or Model 3 was selected to identify critical processing steps between slaughterhouses.

\begin{tabular}{|c|c|c|c|c|c|c|c|c|c|c|c|c|}
\hline & \multicolumn{6}{|c|}{ Campylobacter } & \multicolumn{6}{|l|}{ E. coli } \\
\hline & \multicolumn{2}{|c|}{ Slaughterhouse 1} & \multicolumn{2}{|c|}{ Slaughterhouse 2} & \multicolumn{2}{|c|}{ Both slaughterhouses } & \multicolumn{2}{|c|}{ Slaughterhouse 1} & \multicolumn{2}{|c|}{ Slaughterhouse 2} & \multicolumn{2}{|c|}{ Both slaughterhouses } \\
\hline & Model 1 & Model 2 & Model 1 & Model 2 & Model 1 & Model 3 & Model 1 & Model 2 & Model 1 & Model 2 & Model 1 & Model 3 \\
\hline & Run 1 & Run 1 & Run 2 & Run 2 & Run 5 & Run 1 & Run 3 & Run 3 & Run 4 & Run 4 & Run 6 & Run 2 \\
\hline df & 7 & 21 & 7 & 21 & 7 & 12 & 7 & 21 & 7 & 21 & 7 & 12 \\
\hline AIC & 650.6693 & 662.7846 & 777.0657 & 777.1634 & 1442.054 & 1426.995 & 577.3792 & 593.1349 & 621.8779 & 613.3394 & 1246.27 & 1209.512 \\
\hline $\log$ Lik & -318.3346 & -310.3923 & -381.5329 & -367.5817 & -714.027 & -701.4973 & -281.6896 & -275.5674 & -303.939 & -285.6697 & -616.1486 & -592.7561 \\
\hline Chi-square & 13.791 & & 26.251 & & 33.491 & & 11.344 & & 35.851 & & 58.903 & \\
\hline $\mathrm{p}$ value & 0.465 & & 0.024 & & $3 e-06$ & & 0.659 & & 0.001 & & $2 e-11$ & \\
\hline
\end{tabular}

defeathering minus the predicted concentration after scalding in Slaughterhouse 1 .

\subsubsection{Additional analysis}

Two additional analyses were performed, 1) an ANOVA to analyse whether concentrations after chilling at each slaughterhouse differed between batches for both Campylobacter and E. coli; and 2) a linear regression model (model 4) to analyse the effect of sample type (rinse and skin), organism (Campylobacter and E. coli), slaughterhouse (Slaughterhouse 1 or Slaughterhouse 2) and interaction of organism and slaughterhouse on concentrations after chilling (Concentration).

Concentration $=\beta_{0}+\beta_{1}$ Type $+\beta_{2}$ Organism $+\beta_{3}$ Slaughterhouse $+\beta_{4}$ Organism $*$ Slaughterhouse $+\varepsilon$

\section{Results}

\subsection{Critical processing steps within slaughterhouses}

Different models fitted the data best at different slaughterhouses. Model 1 fitted the data collected in Slaughterhouse 1 best for Campylobacter $(\mathrm{p}=0.465)$ and for E. coli $(\mathrm{p}=0.659)$ (Table 2). Thus, in Slaughterhouse 1, the Campylobacter concentration levels as shown in Fig. 3 and E. coli concentration levels as shown in Fig. 4 varied with respect to the initial external contamination of the batches (concentration in rinse from carcasses collected after bleeding). The impact of the processing steps did not vary over batches in Slaughterhouse 1 (Figs. 3 and 4). Campylobacter concentration on broilers after bleeding in Slaughterhouse 1 varied widely from 2.3 to $6.4 \log _{10} \mathrm{CFU} / \mathrm{ml}$ (Fig. 3) whereas E. coli concentrations varied from 3.1 to $5.7 \log _{10} \mathrm{CFU} / \mathrm{ml}$ (Fig. 4). In Slaughterhouse 2 , model 2 fitted the data best for Campylobacter $(\mathrm{p}=0.024)$ and for E. coli ( $\mathrm{p}=0.001$ ) (Table 2). Thus, in Slaughterhouse 2, Campylobacter concentration levels as shown in Fig. 5 and E. coli concentration levels as shown in Fig. 6 varied with respect to the initial external contamination. In addition, as shown in Figs. 5 and 6, the impact of processing steps varied between batches. Campylobacter concentration on broilers after bleeding in Slaughterhouse 2 varied widely from 1.6 to $6.1 \log _{10}$ CFU/ml (Fig. 5) whereas E. coli concentrations varied from 3.6 to $6.4 \log _{10} \mathrm{CFU} / \mathrm{ml}$ (Fig. 6). Based on the selected models (Model 1 in Slaughterhouse 1 and Model 2 in Slaughterhouse 2) the changes in the Campylobacter and E. coli concentrations in each slaughterhouse were computed as the average increase or decrease per processing step (Table 3). In both slaughterhouses, the concentrations decreased significantly after scalding for Campylobacter by $1.17 \log _{10}$ in Slaughterhouse 1 and by $1.58 \log _{10}$ in Slaughterhouse 2 and for E. coli by $0.64 \log _{10}$ in Slaughterhouse 1 and by $1.29 \log _{10}$ in Slaughterhouse 2 (Table 3 ). Defeathering contributed to a significant increase in the Campylobacter concentration by $0.41 \log _{10}$ in Slaughterhouse 2 ( $p=0.01$ ). No significant differences were found in Slaughterhouse 1 after defeathering in comparison to the concentrations after scalding $(\mathrm{p}=0.92)$. A significant decrease in $E$. coli

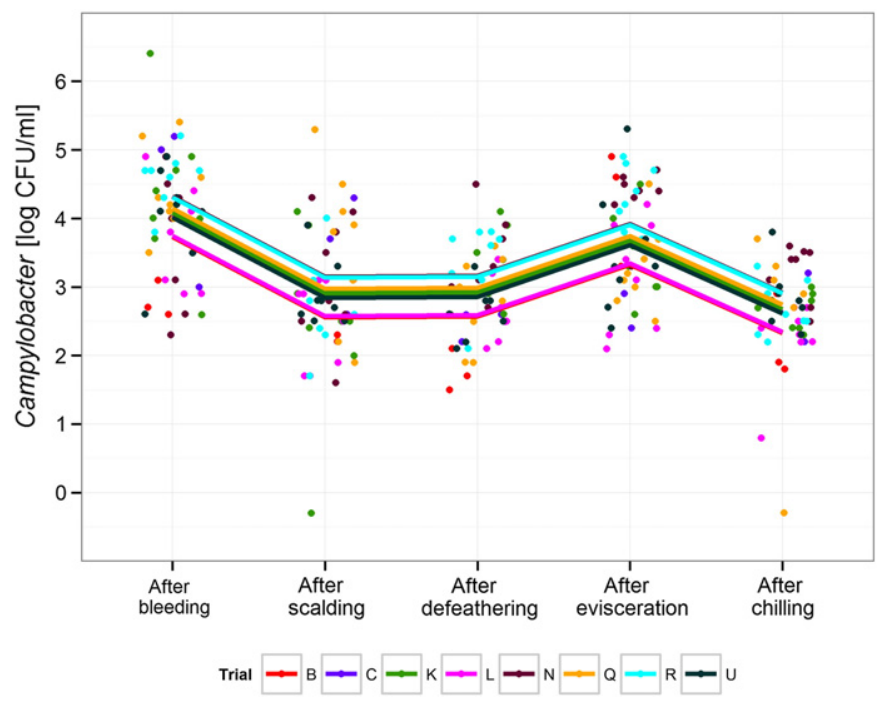

Fig. 3. Campylobacter concentrations in whole broiler carcass rinse samples (log CFU/ml) after selected processing steps in Slaughterhouse 1. The lines indicate the concentrations per sampled batch (trial), based on the selected model (Table 2); the points indicate the concentrations in the individual samples.

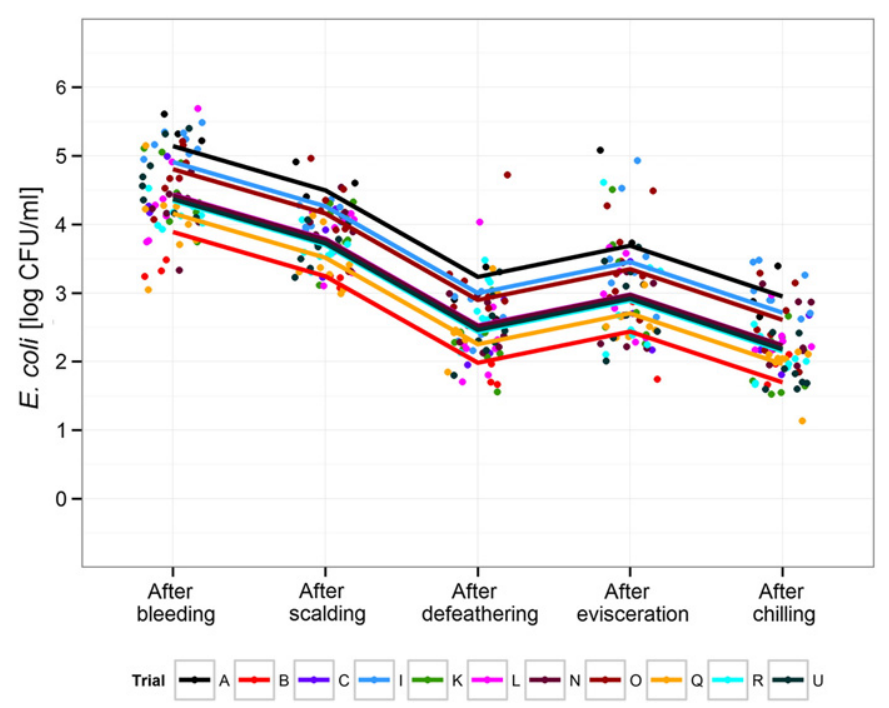

Fig. 4. E. coli concentrations in whole broiler carcass rinse samples (log CFU/ml) after selected processing steps in Slaughterhouse 1 . The lines indicate the concentrations per sampled batch (trial), based on the selected model (Table 2); the points indicate the concentrations in the individual samples. 


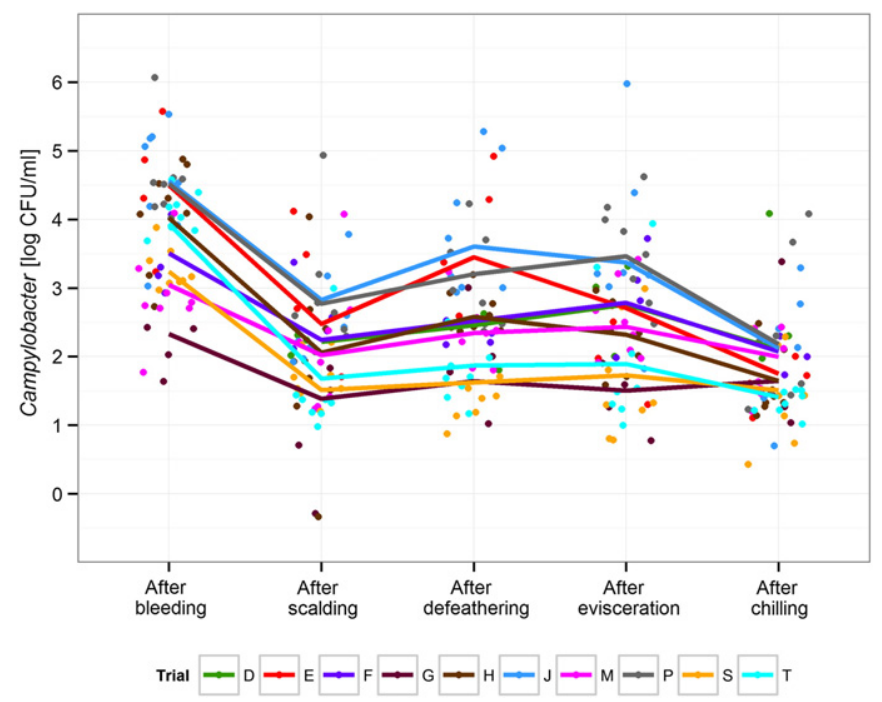

Fig. 5. Campylobacter concentrations in whole broiler carcass rinse samples (log CFU/ml) after selected processing steps in Slaughterhouse 2. The lines indicate the concentrations per sampled batch (trial), based on the selected model (Table 2); the points indicate the concentrations in the individual samples.

concentrations by $1.26 \log _{10}$ in Slaughterhouse 1 and by $0.44 \log _{10}$ in Slaughterhouse 2 after defeathering was found (Table 3). Evisceration in Slaughterhouse 1 caused a significant increase in Campylobacter 0.75 $\left.\log _{10}\right)$ and in E. coli $\left(0.46 \log _{10}\right)$ concentrations. In Slaughterhouse 2, the Campylobacter and E. coli concentration levels after evisceration were not significantly different from the levels after defeathering (Table 3). Significantly lower concentration levels in Campylobacter and E. coli were found after chilling in comparison to concentrations on carcasses collected after evisceration in both slaughterhouses (Table 3). The concentrations on carcasses after chilling, as compared by ANOVA, differed significantly $(\mathrm{p}<0.001)$ between batches in each slaughterhouse.

Average Campylobacter concentration levels were significantly reduced through the processing by $1.40 \log _{10}$ in Slaughterhouse 1 , and also significantly reduced by $1.86 \log _{10} \mathrm{CFU} / \mathrm{ml}$ in Slaughterhouse 2 (Table 3, Figs. 3 and 5). With respect to E. coli, the concentrations after chilling were significantly lower by $2.19 \log _{10}$ in Slaughterhouse 1 and

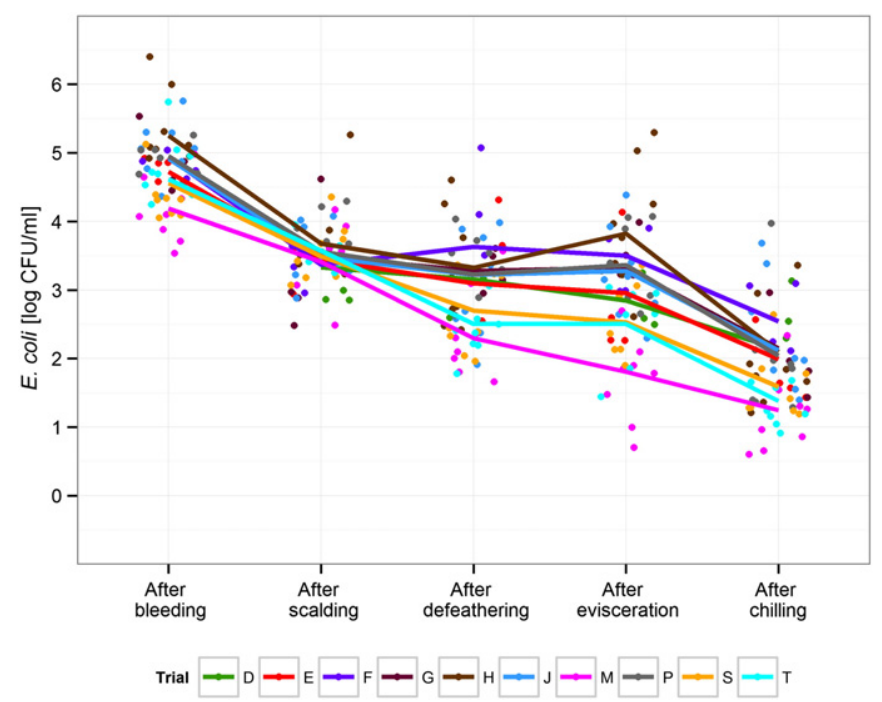

Fig. 6. E. coli concentrations in whole broiler carcass rinse samples (log CFU/ml) after selected processing steps in Slaughterhouse 2. The lines indicate the concentrations per sampled batch (trial), based on the selected model (Table 2); the points indicate the concentrations in the individual samples.
Table 3

Increases and decreases in Campylobacter and E. coli concentrations after selected processing steps. P values $<0.05$ indicate significant increase or decrease in concentrations.

\begin{tabular}{|c|c|c|c|c|c|}
\hline \multirow[b]{2}{*}{ Slaughterhouse } & \multirow[b]{2}{*}{ Processing step } & \multicolumn{2}{|c|}{ Campylobacter } & \multicolumn{2}{|l|}{ E. coli } \\
\hline & & $\log 10$ & $\begin{array}{l}\mathrm{p} \\
\text { value }\end{array}$ & $\log 10$ & $\begin{array}{l}\mathrm{p} \\
\text { value }\end{array}$ \\
\hline \multirow[t]{5}{*}{ Slaughterhouse 1} & Scalding-bleeding & -1.17 & $<0.01^{*}$ & -0.64 & $<0.01^{*}$ \\
\hline & Defeathering-scalding & 0.01 & 0.92 & -1.26 & $<0.01^{*}$ \\
\hline & Evisceration-defeathering & 0.75 & $<0.01^{*}$ & 0.46 & $<0.01^{*}$ \\
\hline & Chilling-evisceration & -1.00 & $<0.01^{*}$ & -0.74 & $<0.01^{*}$ \\
\hline & $\begin{array}{l}\text { Total decrease: } \\
\text { chilling-bleeding }\end{array}$ & -1.40 & $<0.01^{*}$ & -2.19 & $<0.01^{*}$ \\
\hline \multirow{5}{*}{ Slaughterhouse 2} & Scalding-bleeding & -1.58 & $<0.01^{*}$ & -1.29 & $<0.01^{*}$ \\
\hline & Defeathering-scalding & 0.41 & $0.01^{*}$ & -0.44 & $0.01^{*}$ \\
\hline & Evisceration-defeathering & -0.03 & 0.86 & -0.05 & 0.72 \\
\hline & Chilling-evisceration & -0.65 & $<0.01^{*}$ & -1.06 & $<0.01^{*}$ \\
\hline & $\begin{array}{l}\text { Total decrease: } \\
\text { chilling-bleeding }\end{array}$ & -1.86 & $<0.01^{*}$ & -2.84 & $<0.01^{*}$ \\
\hline
\end{tabular}

Significant p values are marked with asterisks.

also significantly lower by $2.84 \log _{10}$ in Slaughterhouse 2 (Table 3 , Figs. 4 and 6).

\subsection{Difference in the effect of processing steps between slaughterhouses}

The impact of slaughterhouse on bacterial concentrations at the processing steps was best described by model 3 for Campylobacter $(\mathrm{p}=3 \mathrm{e}-06)$ (Table 2$)$ and for E. coli $(\mathrm{p}=2 \mathrm{e}-11)$ (Table 2). No significant differences were observed between the slaughterhouses with respect to the Campylobacter and E. coli mean initial contamination level (after bleeding) (Table 4). The average Campylobacter concentration after bleeding in Slaughterhouse 1 was $4.08 \log _{10} \mathrm{CFU} / \mathrm{ml}$, and $3.80 \log _{10} \mathrm{CFU} / \mathrm{ml}$ in Slaughterhouse 2 . The average E. coli concentration after bleeding in Slaughterhouse 1 was $4.48 \log _{10} \mathrm{CFU} / \mathrm{ml}$, and $4.77 \log _{10} \mathrm{CFU} / \mathrm{ml}$ in Slaughterhouse 2.

With respect to Campylobacter concentrations, significant differences in the impact of the processing steps between slaughterhouses were observed after scalding and evisceration. Reduction after scalding was $0.51 \log _{10}$ higher in Slaughterhouse 2 than in Slaughterhouse 1. Evisceration in Slaughterhouse 1 contributed to an increase in concentrations that was $0.78 \log _{10}$ higher than in Slaughterhouse 2 (Table 4). Increase in Campylobacter concentrations after defeathering was higher by $0.39 \log _{10}$ in Slaughterhouse 2 than in Slaughterhouse 1; however, the difference was barely significant $(\mathrm{p}=0.05)$.

With respect to $E$. coli concentrations, significant differences in the impact of the processing steps between slaughterhouses were observed after scalding, defeathering, evisceration and chilling. Reduction after scalding was $0.62 \log _{10}$ higher in Slaughterhouse 2 than in Slaughterhouse 1 (Table 4). Reduction after defeathering in E. coli concentrations

\section{Table 4}

Outcome of Model 3: comparison of the increases and decreases in Campylobacter and E. coli concentration levels at selected processing steps between Slaughterhouses 1 and 2. P values $<0.05$ indicate significant difference in the impact of the processing step between slaughterhouses.

\begin{tabular}{|c|c|c|c|c|}
\hline \multirow[b]{2}{*}{ Processing step } & \multicolumn{2}{|l|}{ Campylobacter } & \multicolumn{2}{|l|}{ E. coli } \\
\hline & $\begin{array}{l}\text { Differences } \\
\text { Slaughterhouse } \\
\text { 1-Slaughterhouse } \\
2 \text { [log10] }\end{array}$ & $\begin{array}{l}\mathrm{p} \\
\text { value }\end{array}$ & $\begin{array}{l}\text { Differences } \\
\text { Slaughterhouse } \\
\text { 1-Slaughterhouse } \\
2 \text { [log10] }\end{array}$ & $\begin{array}{l}\mathrm{p} \\
\text { value }\end{array}$ \\
\hline Bleeding & 0.23 & 0.36 & -0.32 & 0.08 \\
\hline Scalding-bleeding & 0.51 & $0.01^{*}$ & 0.62 & $<0.01^{*}$ \\
\hline Defeathering-scalding & -0.39 & 0.05 & -0.74 & $<0.01^{*}$ \\
\hline Evisceration-defeathering & 0.78 & $<0.01^{*}$ & 0.48 & $<0.01^{*}$ \\
\hline Chilling-evisceration & -0.32 & 0.11 & 0.36 & $0.01^{*}$ \\
\hline Bleeding-chilling & 0.58 & $<0.01^{*}$ & 0.72 & $<0.01^{*}$ \\
\hline
\end{tabular}

Significant p values are marked with asterisks. 


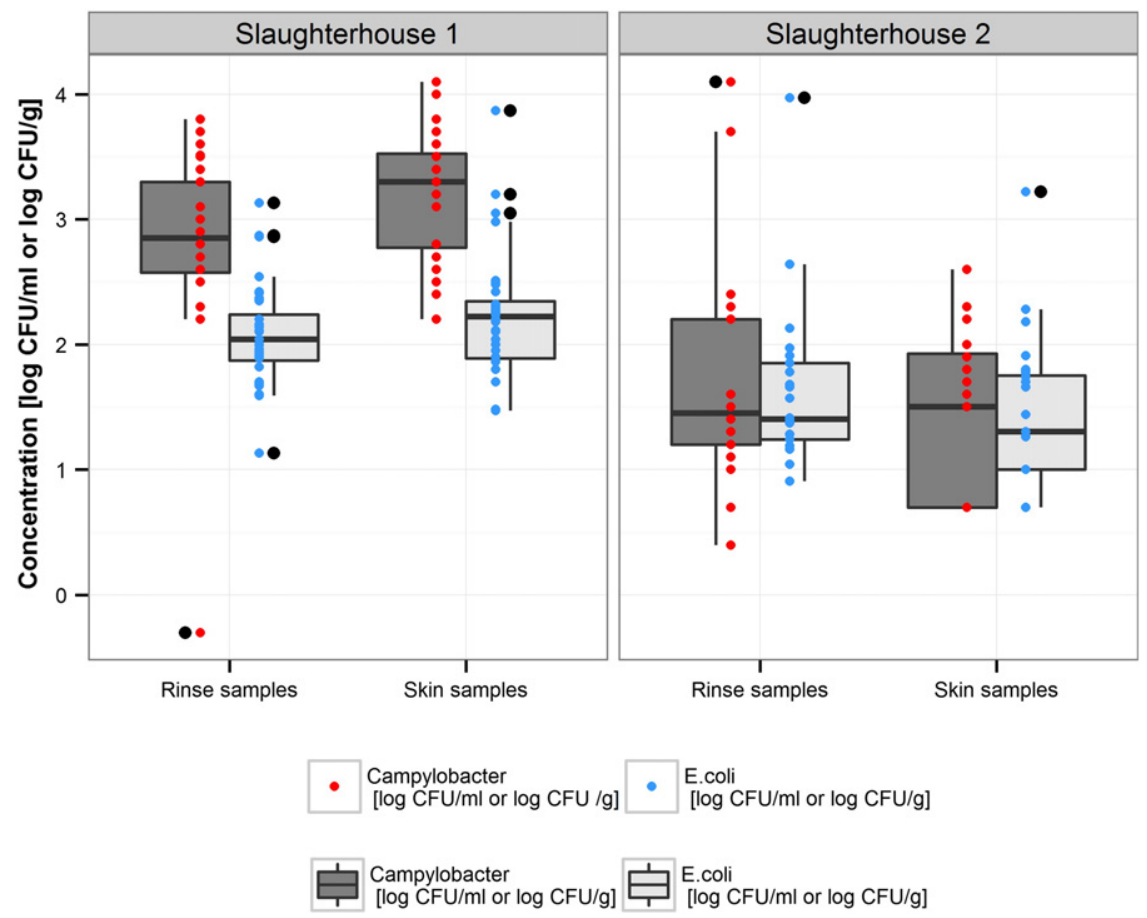

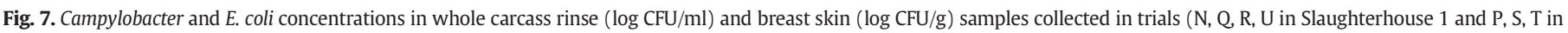

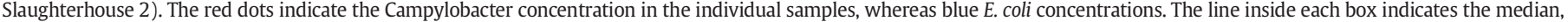
the upper whiskers indicate 75th percentiles and the lower whiskers indicate 25th percentiles. The black dots indicate the outliers.

in Slaughterhouse 1 was $0.74 \log _{10}$ higher than in Slaughterhouse 2. Evisceration in Slaughterhouse 1 contributed to an increase in concentration that was $0.48 \log _{10}$ higher than in Slaughterhouse 2 (Table 4). Decrease in E. coli concentration after chilling was higher in Slaughterhouse 2 by $0.36 \log _{10}$ than in Slaughterhouse 1 (Table 4). Overall reduction through the processing was significantly higher by $0.58 \log _{10}$ for Campylobacter and by $0.72 \log _{10}$ for E. coli in Slaughterhouse 2 than in Slaughterhouse 1.

Based on the linear regression model (model 4), sample type (rinse and skin samples) did not have a significant effect $(p=0.44)$ on Campylobacter and E. coli concentrations after chilling (Fig. 7). Slaughterhouse had significant effect on concentrations after chilling $(\mathrm{p}<2 \mathrm{e}-16)$. The concentrations were significantly lower in Slaughterhouse 2 by 1.41 $\log _{10}$. Organism had significant effect on concentrations after chilling. E. coli concentrations were significantly lower by $0.85 \log _{10}(\mathrm{p}=$ 2.01e - 13) comparing to the baseline (Campylobacter in rinse samples in Slaughterhouse 1). The interaction between slaughterhouse and organism was significant ( $\mathrm{p}=2.23 \mathrm{e}-06$ ), with E. coli in Slaughterhouse 2 lower by $0.8 \log _{10}$ as compared to the baseline.

\section{Discussion}

\subsection{Impact of the processing steps on bacterial concentrations after chilling}

Data collected in this study confirmed that certain slaughterhouses produce carcasses with lower bacterial concentrations after chilling, as previously reported (Anonymous, 2011; European Food Safety Authority, 2010c). This study revealed that, even if the Campylobacter and $E$. coli concentrations in the incoming batches were similar in the studied slaughterhouses, the concentrations after chilling were significantly lower in Slaughterhouse 2 (Fig. 7). The concentration levels in the incoming batches (after bleeding) were highly variable in each slaughterhouse as reported by other studies (Berrang and Dickens, 2000; Oosterom et al., 1983; Seliwiorstow et al., 2012). Our study identified that the pattern of increases and decreases in bacterial concentrations along the processing steps is specific for each slaughterhouse. The pattern was similar in Slaughterhouse 1 for all tested batches. This regularity can be potentially explained by the processing parameters applied consistently for the processed batches even after equipment modernisation. The regular peak after evisceration suggests insufficient control of this step what may have caused higher concentrations after chilling in comparison to Slaughterhouse 2. There the impact of processing steps varied between batches and Campylobacter concentration increased after defeathering. Irregularity in the pattern in Slaughterhouse 2 suggests that, potentially, the control of the processes was not always done in the same way. In-depth analysis of batchrelated characteristics, batch handling operations, processing parameters and hygienic conditions in each slaughterhouse is needed to explain the variations in the observed patterns and its impact on contamination of the carcasses after chilling.

Different patterns of increases and decreases in Campylobacter concentration along the processing steps were included also by different risk assessment models (Nauta et al., 2009); with a slight increase (Nauta et al., 2005) or a considerable decrease (Hartnett et al., 2001) after defeathering and small (Nauta et al., 2005) or large (Hartnett et al., 2001) increases after evisceration. Despite the different dynamics during processing predicted by various models, similar Campylobacter concentration levels after chilling were predicted (Nauta et al., 2009). As shown in the current study however, these levels differed both between slaughterhouses and between batches. Therefore such variability between batches and slaughterhouses can further inform risk assessment models.

Defeathering and evisceration cause an increase in bacterial concentration on carcasses. However based on data collected in our study and on the risk assessment models (Nauta et al., 2009), an increase was not always observed after these steps. The differences in the impact of defeathering and evisceration on Campylobacter concentrations estimated by various models were a consequence of the assumptions made on the faecal contamination during those processing steps (Nauta et al., 2009). It suggests that differences observed in our study in the impact of these processing steps between slaughterhouses could potentially be explained by the degree of control of faecal 
contamination. Such contamination is the major cause of increase in Campylobacter concentration after defeathering and evisceration (Berrang et al., 2001; Berrang et al., 2004; Musgrove et al., 1997; Rosenquist et al., 2006). However, if the concentration on the carcasses entering these processing steps is high, the additional contamination from leaking faeces may not be observed on the log scale. Furthermore, the bacterial concentrations after defeathering and evisceration are not only impacted by faecal leakage and concentration on incoming carcasses, but also by washing. To explain the causes of the differences in the impact of defeathering and evisceration on Campylobacter and E. coli concentrations, a detailed analysis of processing parameters and factors impacting the extent to which the faecal and caecal material contaminate the carcasses is needed.

Our results also confirmed the decrease in Campylobacter and E. coli concentrations after scalding and chilling as previously reported in a review (Guerin et al., 2010). Other authors observed higher reduction in concentrations after scalding than is the case in our study (Berrang and Dickens, 2000). The concentration of Campylobacter decreased after chilling in the analysed slaughterhouses in agreement with other studies (Huezo et al., 2007; Rosenquist et al., 2006). Drying explains the decrease in Campylobacter concentration after chilling (Alter and Scherer, 2006; Murphy et al., 2006; Oosterom et al., 1983). Enterobacteriaceae were reported to be less sensitive to drying than Campylobacter (Oosterom et al., 1983). The observed decrease in Campylobacter and E. coli concentrations after chilling in comparison to concentration after evisceration can additionally be explained by washing prior to chilling.

\subsection{Campylobacter and E. coli along the processing line}

Changes in the concentration levels during processing were similar for both Campylobacter and E. coli except for defeathering (Table 3). In addition, models that fitted Campylobacter data did also fit E. coli data in each slaughterhouse. E. coli concentrations significantly decreased after defeathering in Slaughterhouse 1 by $1.26 \log _{10}$ and in Slaughterhouse 2 by $0.44 \log _{10}$, whereas Campylobacter increased in Slaughterhouse 2 by $0.41 \log _{10}$ and in Slaughterhouse 1 no significant changes were observed. Decrease after defeathering in Enterobacteriaceae (Göksoy et al., 2004; Oosterom et al., 1983) and in Coliforms (Göksoy et al., 2004) was previously reported. The opposite impact of defeathering on Campylobacter and $E$. coli can be related to potential differences in their ability to attach to the skin. Differences within even one bacterial species in the attachment to inert surfaces were previously reported (Hue et al., 2011; Sulaeman et al., 2010). Good correlation of Campylobacter and E. coli during processing was reported (Duffy et al., 2014); however, the defeathering step was not investigated. On the contrary other studies reported weak correlation (Berrang and Dickens, 2000; Williams and Ebel, 2014). Based on orthogonal regression applied for our data, the Campylobacter and E. coli concentrations were not correlated (results not shown). Although there is a lack of correlation, the direction of the changes in concentration (either increase or decrease) is similar for Campylobacter and for $E$. coli at most of the tested processing steps, except for defeathering (Table 3). E. coli has thus the potential to be used as an indicator of the hygienic status of the processing and to be used to identify the critical processing steps; however, more understanding is needed of the opposite impact of defeathering on Campylobacter.

\subsection{Sampling methods}

As the sample type had neither effect on Campylobacter nor on E. coli concentrations (Fig. 7), both methods (whole carcass rinse and breast skin collected after chilling) can be used to evaluate the hygienic status during processing.

Batches sampled during trials $\mathrm{A}, \mathrm{I}$, and $\mathrm{O}$ although determined as positive on farms, resulted in many samples below the detection limit $(50 \%$ in trials A and I) or negative caeca results in the slaughterhouse (trial O). These trials were not informative for the model; hence, they were not included in the analysis. Positive results on the farms versus negative results in the caeca collected in the slaughterhouse can be explained by potential early stage of colonisation in these batches. At the early colonisation stage not all broilers are colonised and the level is low. In future studies, it is advisable to use highly contaminated flocks in order to determine the impact of the processing steps on Campylobacter concentrations. Highly contaminated batches were also reported to result in the major risk for consumers (Nauta et al., 2009).

\section{Conclusions}

Differences in Campylobacter and E. coli concentrations on carcasses after chilling between slaughterhouses are potentially caused by specific increases and decreases in concentrations during processing. Our results confirmed that defeathering and evisceration are the most critical steps during processing, leading to increase in Campylobacter concentrations on carcasses. There are however slaughterhouses that are able to control increases in concentrations after these steps and to maintain the impact of all processing steps at similar levels for each slaughtered batch. Critical processing steps should be validated in each slaughterhouse individually by longitudinal studies and potentially based on E. coli. E. coli has a potential to be used as an indicator of the steps, because the impact of most studied processing steps on E. coli and Campylobacter concentrations was similar, except for defeathering.

\section{Acknowledgements}

This study was financed by MEYN Food Processing Technology B.V., The Netherlands. The authors would like to thank to Willem Heemskerk from MEYN for valuable discussions and the Technology group for support during the field work. Furthermore, we would like to thank the staff in the slaughterhouses for cooperation and support during our field work and the technical staff and interns from the laboratory of the Veterinary Public Health Division for support during the analytical work.

\section{References}

Alter, T., Scherer, K., 2006. Stress response of Campylobacter spp. and its role in food processing. J. Veterinary Med. Ser. B 53, 351-357.

Anonymous, 2000. Microbiology of Food and Animal Feeding Stuffs. Preparation of Test Samples, Initial Suspension and Decimal Dilution for Microbiological Examination. Part 2: Specific Rules for the Preparation of the Initial Suspension and Decimal Dilutions of Meat and Meat Products. Association Française de Normalisation, Paris, France (ISO/CD 6887-2).

Anonymous, 2006. ISO: 10272-2 microbiology of food and animal feeding stuffs - horizontal method for the detection and enumeration of Campylobacter spp. - part 2: colony count technique (ISO/TS 10272-2:2006).

Anonymous, 2010. NEN 6252:2010 Detectie van thermotolerante Campylobacter me Preston en mCCDA in mest en vlees, afkomstig van pluimvee.

Anonymous, 2011. Eindrapportage Convenant Campylobacter aanpak pluimveevlees in $\mathrm{Ne}-$ derland. Resultaten van twee jaar monitoring op de Nederlandse vleeskuikenslachterijen (In Dutch) (Available online: http://www.nepluvi.nl/dynamic/media/1/documents Campylobacter/059 eindrapportage campylobacter convenant 2009-2010.pdf; Last accessed: November 2014. Vereniging van de Nederlandse Pluimveeverwerkende Industrie (NEPLUVI))

Berrang, M., Dickens, J., 2000. Presence and level of Campylobacter spp. on broiler carcasses throughout the processing plant. J. Appl. Poult. Res. 9, 43-47.

Berrang, M., Buhr, R., Cason, J., Dickens, J., 2001. Broiler carcass contamination with Campylobacter from feces during defeathering. J. Food Prot. 64, 2063-2066.

Berrang, M., Smith, D., Windham, W., Feldner, P., 2004. Effect of intestinal content contamination on broiler carcass Campylobacter counts. J. Food Prot. 67, 235-238.

Duffy, L.L., Blackall, P.J., Cobbold, R.N., Fegan, N., 2014. Quantitative effects of in-line operations on Campylobacter and Escherichia coli through two Australian broiler processing plants. Int. J. Food Microbiol. 188, 128-134

European Food Safety Authority, 2010a. Analysis of the baseline survey on the prevalence of Campylobacter in broiler batches and of Campylobacter and Salmonella on broile carcasses in the EU, 2008 - part a: Campylobacter and Salmonella prevalence estimates. EFSA J. 8 (03), 1503. http://dx.doi.org/10.2903/j.efsa.2010.1503 (100 pp. Available online: http://www.efsa.europa.eu/en/efsajournal/pub/1503.htm. Last accessed: November 2014).

European Food Safety Authority, 2010b. Scientific opinion on quantification of the risk posed by broiler meat to human campylobacteriosis in the EU. EFSA J. 8 (1), 1437. http://dx.doi.org/10.2903/j.efsa.2010.1437 (89 pp., Available online: http://www. efsa.europa.eu/en/efsajournal/doc/1437.pdf; Last accessed: November 2014). 
European Food Safety Authority, 2010c. Analysis of the baseline survey on the prevalence of Campylobacter in broiler batches and of Campylobacter and Salmonella on broiler carcasses, in the EU, 2008 - part b: analysis of factors associated with Campylobacter colonisation of broiler batches and with Campylobacter contamination of broiler carcasses; and investigation of the culture method diagnostic characteristics used to analyse broiler carcass samples. EFSA J. 8 (8), 1522. http://dx.doi.org/10.2903/j.efsa. 2010.1522 (Available online: www.efsa.europa.eu/efsajournal; Last accessed: November 2014, 132 pp.).

European Food Safety Authority, 2011. Scientific opinion on Campylobacter in broiler meat production: control options and performance objectives and/or targets at different stages of the food chain. EFSA J. 9 (4), 2105. http://dx.doi.org/10.2903/j.efsa.2011.2105 (141 pp. Available online: www.efsa.europa.eu/efsajournal; Last accessed: November 2014).

European Food Safety Authority, 2012a. Scientific opinion on the public health hazards to be covered by inspection of meat (poultry). EFSA J. 10 (6), 2741. http://dx.doi.org/10 2903/j.efsa.2012.2741 Available online: www.efsa.europa.eu/efsajournal; Last accessed: November 2014, 179 pp.).

European Food Safety Authority, 2012b. Technical specifications on harmonised epidemiological indicators for biological hazards to be covered by meat inspection of poultry. EFSA J. 10 (6), 2764. http://dx.doi.org/10.2903/j.efsa.2012.2764 (87 pp., Available online: www.efsa.europa.eu/efsajournal; Last accessed: November 2014).

European Food Safety Authority, 2014. The European Union summary report on trends and sources of zoonoses, zoonotic agents and food-borne outbreaks in 2012. EFSA J. 12 (2) 3547. http://dx.doi.org/10.2903/j.efsa.2014.3547 (Available online: http://www.efsa. europa.eu/en/efsajournal/doc/3547.pdf; Last accessed: November 2014, 312 pp.).

Göksoy, E.O., Kirkan, S., Kök, F., 2004. Microbiological quality of broiler carcasses during processing in two slaughterhouses in Turkey. Poult. Sci. 83, 1427-1432.

Guerin, M.T., Sir, C., Sargeant, J.M., Waddell, L., O'Connor, A.M., Wills, R.W., Bailey, R.H., Byrd, J.A., 2010. The change in prevalence of Campylobacter on chicken carcasses during processing: a systematic review. Poult. Sci. 89, 1070-1084.

Habib, I., De Zutter, L., Van Huffel, X., Geeraerd, A.H., Uyttendaele, M., 2012. Potential of Escherichia coli as a surrogate indicator for postchill broiler carcasses with high Campylobacter counts. Food Control 25, 96-100.

Hartnett, E., Kelly, L., Newell, D., Wooldridge, M., Gettinby, G., 2001. A quantitative risk assessment for the occurrence of Campylobacter in chickens at the point of slaughter. Epidemiol. Infect. 127, 195-206.

Havelaar, A.H., van Pelt, W., Ang, C.W., Wagenaar, J.A., van Putten, J.P., Gross, U., Newell, D.G., 2009. Immunity to Campylobacter: its role in risk assessment and epidemiology. Crit. Rev. Microbiol. 35, 1-22.

Hue, O., Allain, V., Laisney, M., Le Bouquin, S., Lalande, F., Petetin, I., Rouxel, S., Quesne, S., Gloaguen, P., Picherot, M., Santolini, J., Bougeard, S., Salvat, G., Chemaly, M., 2011. Campylobacter contamination of broiler caeca and carcasses at the slaughterhouse and correlation with Salmonella contamination. Food Microbiol. 28, 862-868.

Huezo, R., Northcutt, J., Smith, D., Fletcher, D., Ingram, K., 2007. Effect of dry air or immersion chilling on recovery of bacteria from broiler carcasses. J. Food Prot. 70, 1829-1834.

Izat, A.L., Gardner, F.A., Denton, J.H., Golan, F.A., 1988. Incidence and level of Campylobacter jejuni in broiler processing. Poult. Sci. 67, 1568-1572.

Klein, G., Reich, F., Beckmann, L., Atanassova, V., 2007. Quantification of thermophilic Campylobacter spp. in broilers during meat processing. Antonie Van Leeuwenhoek 92, 267-273.

Murphy, C., Carroll, C., Jordan, K., 2006. Environmental survival mechanisms of the foodborne pathogen Campylobacter jejuni. J. Appl. Microbiol. 100, 623-632.
Musgrove, M.T., Cason, J.A., Fletcher, D.L., Stern, N.J., Cox, N.A., Bailey, J.S., 1997. Effect of cloacal plugging on microbial recovery from partially processed broilers. Poult. Sci. 76, 530-533.

Nauta, M., Der Fels-Klerx, V., Havelaar, A., 2005. A poultry-processing model for quantitative microbiological risk assessment. Risk Anal. 25, 85-98.

Nauta, M., Evers, E., Havelaar, A., Bolder, N., Van der Wal, F., Rijsman, V., Horne, P.v., 2007. Risicobeheersing van Campylobacter in de pluimveevleesketen. (In Dutch) Rapport/ Animal Sciences Group 07/100521.

Nauta, M., Hill, A., Rosenquist, H., Brynestad, S., Fetsch, A., van der Logt, P., Fazil, A., Christensen, B., Katsma, E., Borck, B., Havelaar, A., 2009. A comparison of risk assessments on Campylobacter in broiler meat. Int. J. Food Microbiol. 129, 107-123.

Oosterom, J., Notermans, S., Karman, H., Engels, G., 1983. Origin and prevalence of Campylobacter jejuni in poultry processing. J. Food Prot. 46, 339-344.

Pacholewicz, E., Swart, A., Lipman, L.J.A., Wagenaar, J.A., Havelaar, A.H., Duim, B., 2013. Propidium monoazide does not fully inhibit the detection of dead Campylobacter on broiler chicken carcasses by qPCR. J. Microbiol. Methods 95, 32-38.

Reich, F., Atanassova, V., Haunhorst, E., Klein, G., 2008. The effects of Campylobacter numbers in caeca on the contamination of broiler carcasses with Campylobacter. Int. J. Food Microbiol. 127, 116-120.

Rosenquist, H., Sommer, H.M., Nielsen, N.L., Christensen, B.B., 2006. The effect of slaughter operations on the contamination of chicken carcasses with thermotolerant Campylobacter. Int. J. Food Microbiol. 108, 226-232.

Seliwiorstow, T., Baré, J., Uyttendaele, M., De Zutter, L., 2012. Quantitative monitoring of the Campylobacter contamination of broiler carcasses during slaughter. Presentation during IAFP's European Symposium on Food Safety 21-23 May 2012; Warsaw, Poland (Available online: https://www.foodprotection.org/downloads/meetings/program-activities/ programs/tomasz-seliwiorstow-quantitative-monitoring-of-the-em-campylobacterem-contamination-of-broiler-carc.pdf; Last accessed: November 2014).

Sulaeman, S., Le Bihan, G., Rossero, A., Federighi, M., Dé, E., Tresse, O., 2010. Comparison between the biofilm initiation of Campylobacter jejuni and Campylobacter coli strains to an inert surface using BioFilm Ring Test ${ }^{\circledR}$. J. Appl. Microbiol. 108, 1303-1312.

Swart, A., Mangen, M.J., Havelaar, A.H., 2013. Microbiological criteria as a decision tool for controlling Campylobacter in the broiler meat chain. Report of Dutch National Institute for Public Health and the Environment (RIVM) Report 330331008 (Available online: http://www.betelgeux.es/images/files/Externos/Campylobacter.pdf; Last accessed: November 2014)

Tchórzewska, M., Harrison, D., Morris, V., Hutchison, M., Allen, V., 2013. Investigations of changes to campylobacter numbers on broiler carcasses during and following processing. Proceedings of the 17th International Workshop on Campylobacter, Helicobacter and Related Organisms, 15-19th September 2013, Aberdeen, Scotland, UK (Available online: http://jmm.sgmjournals.org/content/suppl/2013/08/30/62.Pt_ 9.DC1/CHROfinal.pdf; Last accessed: November 2014).

Williams, M.S., Ebel, E.D., 2014. Estimating the correlation between concentrations of two species of bacteria with censored microbial testing data. Int. J. Food Microbiol. 175, $1-5$

Williams, M.S., Ebel, E.D., Golden, N.J., Berrang, M.E., Bailey, J.S., Hartnett, E., 2010. Estimating removal rates of bacteria from poultry carcasses using two whole-carcass rinse volumes. Int. J. Food Microbiol. 139, 140-146. 